\title{
Alford's theoretical political framework and its application to interests in health care now
}

\section{INTRODUCTION}

In these troubled times, it can be useful to see whether there are any sociological or political theories that could help us analyse issues from a fresh perspective. Several theories might be relevant but Alford's political theory of interests seems to me especially illuminating. Published in 1975 , it is based on Robert R Alford's study of the failure of reforms to improve health care in New York city. ${ }^{1}$ Its detailed categorisation of interest holders and examination of the political relationships among them, and its general applicability to western healthcare systems, promise to make sense of conflicts of objective and of view in debates about proposed policies and changes in UK health care. Here I outline Alford's theory and look at the convergences and conflicts of interests among the major categories of interest holders he identifies: clinicians, corporate rationalisers, and patients. (Corporate rationalisers is a useful term for bureaucrats, managers, and many academics, see below.) Patients' interests are excluded from discussions about proposed policies more often than other interest holders always realise or intend. Using Alford's framework, I suggest that a more thorough consideration of the interests of all three categories of interest holder could sometimes lead to policies that met the interests of them all.

\section{ALFORD'S 1975 THEORY OF POLITICAL INTERESTS}

Alford's theory is expressed through the political concepts of interests and power. Interests are difficult to define but roughly mean a stake in something that is important to the interest holder because of the benefit or harm it can do to him or her or to the social group to which he or she belongs. ${ }^{2}$ Power is ability to bring about significant effects, specifically by furthering the agent's own interests or by affecting the interests of others, whether positively or negatively. ${ }^{2}$ Values, the worth of something to a person or group, are closely linked to people's view of their own interests; if someone values something, he or she has, or holds, an interest in it.

Alford put interests in health care into three categories.

- Dominant interests are held by professional monopolists - health professionals, especially doctors in clinical practice - having or seeking clinical autonomy and concerned primarily with individual patients. ${ }^{1}$ Dominant interest holders and groups in health care have authority to define the meanings of disease and health care and to secure compliance with their own policies or to veto other interest holders' policies. ${ }^{1,3}$ The recent successful revolt by consultants against the new system for appointing junior doctors to training posts demonstrates that clinicians remain the dominant power group, if they choose to use their power.

- Challenging interests are held by corporate rationalisers - civil servants in government health departments carrying out the wishes of politicians, executive health service managers, public health doctors, deans of medical schools, many academic commentators on health care, and health services seeking the rational use of resources for defined populations of patients. ${ }^{1}$ Corporate rationalism is roughly synonymous with managerialism and with bureaucracy. Civil servants are bureaucrats and executive managers practice managerialism, but both are corporate rationalisers since they hold many of the same values and interests. These key values are the cost-effective use of resources, standardisation, predictability, regulation, audit, and control. ${ }^{1,4}$ Control includes control over the professional and clinical work of clinicians. ${ }^{1,4}$

- Repressed interests are held by 'the community' whose 'equal healthcare advocates' seek accessible, equitable, free, high-quality health care for everyone. 'In the UK 'the community' corresponds to patients and the public; their advocates are called patient advocates, activists, or representatives. Alford termed these interests repressed because there were few people to speak for, that is, represent, patients' or the public's interests on policy-making or decision-making bodies at any level of the US health system. In the UK, although more people are now appointed to advisory and other bodies to speak for the public's and patients' interests than in the past, these interests are still pervasively repressed. Here are some instances.

Although many policy- and decisionmaking bodies, committees, or working parties have one or two lay or patient members, confusion about who exactly can speak for whose interests is common. Lay people, members of the public, 'ordinary' patients (those not politically engaged with the health service through trying to improve patient care), and patient advocates overlap but have different types and levels of experiential and specialist knowledge. ${ }^{5,6}$ Failure to appreciate this can lead to the appointment of people unsuited for the scope and level of the group's work.

When individuals who have enough 
expertise to speak for other patients' interests are appointed or are in place to be consulted, health professionals and managers are not obliged to seek their views. Although trusts in London consulted patient groups about some aspects of the mental health services, their views were not sought on crucial issues like the restraint of patients. ${ }^{7}$ The views of 'ordinary' patients about their own experiences can fare no better. A handbook for staff in York about how to elicit patients' views advised staff not to invite comments on 'sensitive' topics or ones that staff themselves could not act on. ${ }^{8}$

When the public's views are sought through large-scale consultations, the findings can be disregarded.

Some policies and practices are concealed from patients and the public who, therefore, cannot judge whether or not they are in their interests, as they would define them. Not telling patients who might need a blood transfusion after elective surgery that their own blood, collected in advance, could be used instead of donor blood, is an example. ${ }^{9}$

Alford knew that his three major groups of interest holders included subgroups with slightly different interests. ${ }^{1} \mathrm{He}$ also saw that members of one major interest group could support some of the interests of another major group. In 1975, the support of patients and the public for clinicians' interests and values was taken for granted and sustained doctors' dominance. It still does; and even some patient advocates support dominant or challenging interests and values when they conflict with those of patients as well as when they converge. Similarly, some medically-qualified persons and many lay policy analysts, advisors, and commentators are corporate rationalisers. ${ }^{1}$ These deviations from what might be expected are little recognised, by themselves or by others.

Health care and health services have become more complex since Alford's day. The pharmaceutical industry, private healthcare and insurance companies have become more prominent, and new paraprofessional groups take part in clinical practice. Dominant interest holders are now subject to strong and sometimes successful challenges from corporate rationalisers. ${ }^{10,11}$ They are also now subject to weak and often unsuccessful challenges from patient advocates. ${ }^{3}$ But even when dominant interest holders accept other groups' proposed policies, they often modify or subvert them to their own ends. ${ }^{3,12}$ The basic dynamics of conflicts and convergences of interests have not changed. In the following sections, I look at how Alford's concepts are still relevant today.

\section{PATIENTS' AND THE PUBLIC'S REPRESSED INTERESTS COMPARED WITH CORPORATE RATIONALISERS' AND PROFESSIONAL MONOPOLISTS' INTERESTS}

Patients are both individuals and members of patient populations: they want good care for themselves and for other patients. How 'good care' is defined changes over time. Patient autonomy is a key value in the early 21 st century and is supported directly through information, choice and shared decision making and indirectly through respect, access, equity, safety, support, redress, and representation. ${ }^{12,13}$

But the repression of patients' interests means that it is not always easy to be certain what 'ordinary' patients, carers or members of the public would say that their interests were, if they knew how their interests might be affected by policies and practices unknown or misrepresented to them. ${ }^{9}$ By contrast, how professional monopolists and corporate rationalisers define their own interests and values are, respectively, well understood and fairly well understood. In Table 1, some of the patient positions are provisional, pieced together from evidence and argument from several sources.

The rationale for each patient position are shown in Box 1.

The positions in Table 1 characterise typical corporate rationalisers, professional monopolists and patients. They show that the interests of each group zig-zag between the other two: sometimes converging, sometimes conflicting. Similar tables could be drawn up for other sets of issues.

\section{MIXED POSITIONS}

The positions in Table 1 are typical of each set of interest holders. But real individuals, as distinct from ideal types, can hold varying and mixed positions, depending on their alignments (not necessarily clearlydefined or consciously held), their role in the health service and the specific issues. Some patients choose to leave decisions to their doctors. ${ }^{15}$ GPs can feel tension between 'professional' (professional monopolist) and 'practice' (corporate rationalist) values. ${ }^{24}$ Some clinicians in partclinical, part-managerial roles promote corporate rationalism; they are "corporate rationalisers from within."11 Others comply with corporate rationalist policies while complaining about them privately. So individuals' alignments can be obscure. This recalls Alford's point that interest holders sometimes support some of the interests of other groups, even when those interests apparently conflict with those of their own group. ${ }^{1}$ Because clinicians are dominant interest holders, corporate rationalisers and patient advocates must gain their support for changes to policies and practices. Mixed positions and confusion about alignments sometimes hinder, sometimes facilitate, this.

\section{INTERESTS AND POLICIES}

Patients' interests are not so completely repressed, so little articulated or heeded, that corporate rationalisers and professional monopolists are unaware of any conflicts between their interests and those of patients. But a notable feature of almost every discussion of relationships and shifts of power between corporate rationalisers and clinicians, of reorganisations of the health service or of the future of medicine, is the absence of any serious reference to patients' interests and values.

Major policies have been devised and implemented with little, if any, consultation with the public, patients, or patient advocates. Yet consultation could sometimes lead to policies that met patients' interests at the expense of only slight modifications to corporate rationalisers' or clinicians' initial assumptions about how their own interests could be protected. Referral management is an example. 
Table 1. Corporate rationalisers', professional monopolists', and patients' interests and values compared.

\begin{tabular}{|c|c|c|}
\hline Corporate rationalisers & Professional monopolists & Patients \\
\hline $\begin{array}{l}\text { Rational, that is, planned and efficient use } \\
\text { of resources }^{1}\end{array}$ & Resources according to professionally-defined need ${ }^{4}$ & $\begin{array}{l}\text { According to need as defined by doctor } \\
\text { and patient }(\text { i) }\end{array}$ \\
\hline For populations of patients ${ }^{1}$ & For individual patients ${ }^{1,4}$ & For both populations and individuals(ii) \\
\hline Economic efficiency the goal ${ }^{4}$ & Quality the goal ${ }^{4}$ & $\begin{array}{l}\text { Quality the goal but quality includes } \\
\text { some efficiencies(iii) }\end{array}$ \\
\hline $\begin{array}{l}\text { Aim to reduce professionals' discretion as } \\
\text { much as possible, to maximise efficiency } \\
\text { and predictability }{ }^{4}\end{array}$ & Professionalism intrinsically at odds with managerialism ${ }^{4}$ & $\begin{array}{l}\text { Not known, but doctors more trusted } \\
\text { than managers(iv) }\end{array}$ \\
\hline Control of clinicians' patterns of working ${ }^{4}$ & Free to work as think best, control own work ${ }^{4}$ & $\begin{array}{l}\text { Probably managerial control over } \\
\text { patterns of working but not over clinical } \\
\text { decisions }(v)\end{array}$ \\
\hline Abolition of clinical autonomy ${ }^{4}$ & Preservation of clinical autonomy ${ }^{4}$ & Preservation of clinical autonomy(vi) \\
\hline $\begin{array}{l}\text { Replacement of highly qualified professionals } \\
\text { by cheaper ones }{ }^{4}\end{array}$ & Resist or doubtful about such replacements & Problematic(vii) \\
\hline $\begin{array}{l}\text { A small number of highly qualified professionals } \\
\text { to become consultants to other staff }\end{array}$ & $\begin{array}{l}\text { Highly qualified professionals in direct relationships } \\
\text { with patients }{ }^{4}\end{array}$ & $\begin{array}{l}\text { Highly qualified professionals as } \\
\text { consultants to patients(viii) }\end{array}$ \\
\hline Guidelines and protocols compulsory ${ }^{19}$ & $\begin{array}{l}\text { Guidelines and protocols discretionary - essence of } \\
\text { professionalism is knowledge and judgement }{ }^{4}\end{array}$ & $\begin{array}{l}\text { Guidelines and protocols to be offered to } \\
\text { patient, then shared decision making(ix) }\end{array}$ \\
\hline Promote information and choice for patients ${ }^{1}$ & Slow to offer information and choice, ${ }^{1}$ & $\begin{array}{l}\text { Value full information, choice of } \\
\text { treatment }(\mathrm{x})\end{array}$ \\
\hline Support innovation ${ }^{1}$ & Clinicians often resistant to change $\mathrm{e}^{1,12}$ & $\begin{array}{l}\text { Support innovation in response to } \\
\text { patients' views and requests(xi) }\end{array}$ \\
\hline $\begin{array}{l}\text { Regulation heavy, managers and lay } \\
\text { people in majority }\end{array}$ & Regulation light, professionals predominate & $\begin{array}{l}\text { Regulation heavy, (xii) should include lay } \\
\text { people }\end{array}$ \\
\hline Belief in money as motivator ${ }^{23}$ & Belief in altruism as motivator ${ }^{23}$ & $\begin{array}{l}\text { Probably both, like most people(xii) should } \\
\text { include lay people }\end{array}$ \\
\hline
\end{tabular}

The Roman numerals refer to paragraphs in the rationale in Box 1.

\section{REFERRAL MANAGEMENT}

Referral management is a new system in which GPs' and consultants' referrals are scrutinised by a doctor or manager in a referral centre and forwarded, redirected or barred..$^{25}$ Corporate rationalist reasons for promoting it included sending patients to services that are either cost-effective or underused. ${ }^{25}$ Other reasons, scarcely spelled out to GPs, patients, or the public, included getting data on each GP's referrals to check against trusts' claims for payments; checking whether GPs were complying with national and local guidelines; edging out GPs' clinical autonomy; gaining more control over them and their patients; and weakening the bond between patient and GP and patient and consultant. This weakening was put in motion through inducing GPs to switch their patients from a personal to a practice list. Although patients can choose which GP to consult, GPs have allowed restrictive policies to be imposed on their patients as well as on themselves.

GPs' reasons for opposing referral management included the threat to their clinical autonomy and to 'patient choice of hospital', and the delicacy of persuading some reluctant patients to accept referral. ${ }^{25,26}$ But patient issues, that is, issues where the interests of patients are likely to diverge markedly from those of clinicians or corporate rationalisers, have received scant attention. First is patient autonomy as realised through the GP's and the patient's shared decisionmaking, with its tacit or explicit negotiation in which each is free to request or refuse referral, and where the interests of each, as each defines them, manifestly converge or conflict. From patient autonomy follow issues of patients' consent or refusal to their shared decision being reviewed by someone not directly involved in their care, to confirm or overturn that decision; who the reviewer will be and how the patient will be told who he or she is; how a decision to overturn their GP's advice is to be explained truthfully to the patient; what the patient's right of appeal will be; to whom the reviewer is accountable; and whether the reviewer will have access to the patient's electronic health record, and if so, how consent is to be sought. Although scrutiny of referrals could perhaps sometimes be to a patient's advantage, changing the doctor-patient relationship to bring a third person into it should have had extensive public, patient, and patient activist debate first. It had none.

Other ways of securing 'better' referrals could be designed if patients were seen as partners in their health care. If they were routinely offered the national or local referral guidelines for the condition or disease they or their GP suspected, patients (who wished to) and their GP 


\section{Box 1. Rationale for the patient positions.}

i. Shared decision-making is increasingly desired and expected by patients. ${ }^{14}$ Patients know that rationing may be taking place and many would like their doctor to tell them about treatments that are not affordable. ${ }^{9,15}$

- ii. The vulnerabilities and vicissitudes of life make concern for populations, not just the self, prudent. Besides, some patients are altruistic. ${ }^{16}$ They know that others need health care and want to see resources used equitably and efficiently, for the common good, ${ }^{17}$ although they hope that their doctor will not jeopardise their own welfare through rationing. ${ }^{18}$

- iii. Patient advocates have been trying to raise standards of care since the $1960 \mathrm{~s}^{12}$ and high quality healthcare includes the timely provision of services, information, and so on. As well as the abolition of ineffective or harmful procedures and treatments.

- iv. How patients perceive and judge professionalism (professional monopolism) compared to managerialism (corporate rationalism) is not known, but they value aspects of care, such as continuity of relationship with the same doctor, that require management. ${ }^{15}$

- v. Clinicians' work in technologically and organisationally complex environments requires management; only corporate rationalisers can deliver some aspects of provision and care that support patients' interests. ${ }^{19}$

- vi. Patients expect their clinicians to respect their autonomy. ${ }^{14}$ To do that, clinicians need clinical autonomy to be free to explore with their patients all relevant diagnostic and treatment options, to say what can and cannot be provided locally (with regard to resources, equipment, skill, and clinicians' preferences), and to help patients decide on a course of action, if necessary advising them to go elsewhere.

- vii. The above issue is problematic because some surveys show that the public and patients would accept less-qualified staff in place of qualified ones, provided that their care were safe (Personal communication, member of staff of Modernisation Agency, 2004). But some patient advocates doubt whether safety can be secured and high standards of patient care safeguarded. So there could be significant differences of view between patients.

viii. Hospital doctors and other types of clinician seldom introduce themselves by grade, so patients can find it hard to know who is treating them. But shared decision making means that patients need easy access to highly-qualified professionals who have the knowledge and the authority to make decisions with them. See vi and vii.

- ix. Once patients are made aware that guidelines and protocols exist, many want to see, or have the option of declining to see, those relevant to their referral or treatment. Patients' difficulties in getting hold of the protocols under which they suppose they are being treated are exemplified by one patient's account of her treatments for glaucoma. ${ }^{20}$

- x. Surveys over the last 40 years have repeatedly shown that many patients want more information than they are offered. ${ }^{21}$ Patient advocates believe that patients should be offered comprehensive, evidence-based, unbiased and truthful information. Withholding information is a means of controlling patients. ${ }^{9}$

- xi. Some clinicians resist higher standards, as patient advocates define them, even when those standards are adopted by professional bodies. ${ }^{12}$ Depending on their agendas and priorities, corporate rationalisers sometimes promote, sometimes ignore, standards that patients and patient advocates want put in place.

- xii. Many members of the public believe that doctors are already regularly assessed for competence and think that they should be. ${ }^{22}$ In total, $52 \%$ of members of the public thought that doctors and expert lay people should assess doctors whereas $60 \%$ of doctors thought assessment should be solely by doctors. ${ }^{22}$

- xiii. Corporate rationalisers incline to believe that money motivates; professional monopolists hope it does not. ${ }^{23}$ Revelations that doctors can earn extra money by meeting targets, for example for immunisation or for recruiting patients into clinical trials, can undermine the public's esteem for the profession. Once patients find out about the Quality and Outcomes Framework, they cannot trust that their doctor's advice is based on their clinical judgement rather than on their wish to meet targets. If the doctor explains about targets, the patient may feel obliged to accept the advice for the doctor's sake. If the doctor does not explain, the patient may feel deceived. Whether financial incentives should form part of the 'modern NHS' has not been debated publicly.

could go through them together and discuss whether or not the guideline should be followed in the light of the patient's individual predicament and any other information the GP or patient might have. That would protect the patient's safety. It would respect the relationship or bond between GP and patient and would uphold the autonomy of both the GP and the patient. GPs would become accustomed to following referral protocols, even for patients who did not wish to discuss them. That would help secure corporate rationalisers' interests in costeffective, uniform standards of care that reduced inequities. The repression of patients' interests through referral management and its dubious ethics would be overcome.

\section{USING ALFORD'S FRAMEWORK: SOME POINTS FOR ACTION}

Alford's theory and categorisations can help us understand how dominant and challenging interest holders see their interests and so understand the reasons behind their proposals and policies, even when they do not declare them. We now know more about how patients' define their interests than Alford did, but as those interests are still pervasively repressed, they still fit into his framework. People currently considering proposed policies should be able to analyse potential conflicts and convergences of interests among the three categories of interest holders with more thoroughness than marked consideration of policies like referral management. All proposed policies require open, informed, detailed, and honest explanation and debate between all three sets of interest holders. This could go some way towards releasing patients' interests from repression as well as leading to policies that were acceptable to all interest holders.

Questions of how far individual patients' interests converge or conflict with those of other patients or of the patient population need more careful analysis and less arbitrary answers than they have customarily had. They should not be used as an excuse for excluding patients and patient advocates from decisions or from policy making.

Dominant interest holders seem to be tending towards accepting corporate rationalism in western medicine. That is 
probably inevitable because of the increasing technology of medicine, its rising costs, and the need for team working. ${ }^{19}$ Moreover, some aspects of corporate rationalism meet some of the interests of patients more closely than professional monopolism can (Table 1). ${ }^{19}$ Nevertheless, new policies should only be accepted after thorough consideration of their cumulative implications. Corporate rationalisers have found ways of influencing clinicians through financial incentives. But clinicians should bear in mind that patients may fail to see the difference between a new expense, not yet covered in the ordinary way, and a bribe.

Corporate rationalisers at every level need also to think through the implications of the policies they promote. The Chief Medical Officer for England observes that financial and activity targets have higher current priorities than quality and safety. ${ }^{22}$ That is a criticism of corporate rationalisers (politicians, civil servants, managers, and trust board nonexecutive directors) as well as a comment on a lack of attention to quality and safety in the NHS.

A distinction may be drawn between corporate rationalism as a set of principled beliefs and the more transient predilections and aspirations of political parties, although they are linked in the UK through civil servants in the Department of Health in England, or its Scottish or Welsh equivalents, and the government of the day. For instance, the government's introduction of commercialism into the $\mathrm{NHS}$ is carried out by managers but is not an integral part of corporate rationalism. Most business people appointed to positions in the Department of Health or to trust boards, however, can be assumed to be corporate rationalisers. That is why they are appointed.

How far repressed interest holders, the public and patients, accept which aspects of corporate rationalism is unknown, partly because the full implications and consequences of proposed policies are seldom explained to them. Patient advocates have scarcely begun to consider corporate rationalist interests and values as carefully as they have considered professional monopolist interests. They must.

\section{CONCLUSION}

Corporate rationalism is partly a response to dominant interest holders' past waste of resources and inability or unwillingness to ensure that all patients were offered health care to acceptable standards. Patient advocacy is partly a response to dominant interest holders' inability or unwillingness to ensure reasonable standards for all patients, and to their sometimes coercive approach to patients and lack of respect for their autonomy. It is important that clinicians as dominant interest holders consider how far they can meet the wishes and evidence-based requests of corporate rationalisers and of patients and patient advocates, while retaining and developing or refining those aspects of their professionalism that give clinicians their unique value to society.

\section{Charlotte Williamson}

\section{Acknowledgements}

I thank Liz Cairncross and Patricia Wilkie for their helpful comments.

\section{REFERENCES}

1. Alford RR. Health care politics, ideological and interest group barriers to reform. Chicago, IL: Chicago University Press, 1975

2. Lukes S. Power. A radical view. 2 nd edn. Basingstoke: Palgrave Macmillan, 2005.

3. Salter B. The new politics of medicine. Basingstoke: Palgrave Macmillan, 2004.

4. Freidson E. Professionalism, the third logic. Oxford: Polity Press, 2001.

5. Williamson C. The rise of doctor-patient working groups. BMJ 1998; 317: 1374-1377.

6. Hogg C, Williamson C. Whose interests do lay people represent? Towards an understanding of the role of lay people as members of committees. Health Expectations 2001; 4: 2-9.

7. Rutter D, Manley C, Weaver T, et al. Patients or partners? Case studies of user involvement in the planning and delivery of adult mental health services in London. Soc Sci Med 2004; 58: 1973-1984.

8. York Health Services NHS Trust. User involvement toolkit. York: York Health Services NHS Trust, 2002.

9. Williamson C. Withholding policies from patients restricts their autonomy. BMJ 2005; 331: 1078-1080.
10. Hunter DJ. From tribalism to corporatism: the continuing challenge to medical dominance. In: Kelleher D, Gabe J, Williams G (eds). Challenging medicine. 2nd edn. Abingdon: Routledge, 2006: 1-23.

11. North N, Peckham S. Analysing structural interests in primary care groups. Social Policy and Administration 2001; 35: 426-440.

12. Williamson C. Whose standards? Consumer and professional standards in health care. Buckingham: Open University Press, 1992.

13. Williamson C. The patient perspective on information. In: Lack JA, Rollin AM, Thoms G, et al (eds). Raising the standard: information for patients. London: Royal College of Anaesthetists, 2003: 73-76.

14. Coulter A, Magee H. The European patient of the future. Maidenhead: Open University Press, 2003.

15. Chisholm A, Cairncross L, Askham J. Setting standards. The views of patients, members of the public and doctors on the standards of care and practice they expect of doctors. Oxford: Picker Institute Europe, 2005.

16. Edwards NP. Birthing autonomy, women's experiences of planning home births. London: Routledge, 2005.

17. Coulter A. What do patients and the public want from primary care? BMJ 2005; 331: 1199-1200.

18. Mechanic D. In my chosen doctor I trust. BMJ 2004; 329: 1418-1419.

19. Schneider C E. The practice of autonomy, patients, doctors, and medical decisions. New York and Oxford: Oxford University Press, 1998.

20. McColl E. I just want the protocol, doctor! Qual Saf Health Care 2005; 14: 155.

21. Picker Institute Europe. Is the NHS getting better or worse? An in-depth look at the views of nearly a million patients between 1998 and 2004. Oxford: Picker Institute Europe, 2005.

22. Donaldson L. Good doctors, safer patients. London: Department of Health, 2006.

23. Le Grand J. Motivation, agency, and public policy. Oxford: Oxford University Press, 2003.

24. Pratt J. Practitioners and practices, a conflict of values? Oxford: Radcliffe Medical Press, 1995.

25. Davies M, Elwyn G. Referral management centres: promising innovations or Trojan Horses? BMJ 2006; 332: 844-846.

26. Heath I. Commentary: patients are not commodities. BMJ 2006: 332: 846-847.

DOI: 10.3399/bjgp08X319558 